\title{
Desarrollo de la Piel y sus Anexos en Vertebrados
}

\author{
Skin and Appendages Development in Vertebrates
}

\author{
"Manuel Meruane \& ** Mariana Rojas
}

MERUANE, M. \& ROJAS, M. Desarrollo de la piel y sus anexos en vertebrados. Int. J. Morphol., 30(4):1422-1433, 2012.

RESUMEN: La Piel y sus estructuras asociadas permiten a los seres vivos subsistir en los diferentes ambientes ecológicos. El desarrollo de la piel y sus anexos en diferentes especies repite patrones comunes. De suma importancia es la interacción epiteliomesénquima como regulador inicial de este desarrollo. El evento crucial en la formación de anexos, es la aparición de una placoda ectodérmica, a la cual se le asocia una condensación de células dérmicas, expresándose proteínas como Sonic Hedgehog (SHH) y la proteína morfogenética del hueso (BMP) para luego dar forma al anexo de cada especie. En esta revisión describiremos las etapas sucesivas que transcurren en la formación de la dermis, epidermis y anexos, con énfasis en las proteínas que dirigen el proceso.

PALABRAS CLAVE: Piel; Dermis; Epidermis; Anexos.

\section{INTRODUCCIÓN}

La piel y sus estructuras asociadas permiten a los seres vivos vivir en los diferentes ambientes ecológicos. La primera y más importante función es establecer una barrera entre el organismo y el medio ambiente, manteniendo así la homeostasis interna, reduciendo la fricción de los elementos externos y protegiendo de rasguños y picaduras de predadores. Adicionalmente la pigmentación y el olor de las glándulas cutáneas permiten una comunicación social y sexual.

Con el objeto de adaptarse a todas las funciones, el tegumento de los vertebrados ha desarrollado una amplia variedad de anexos dentro de los cuales se encuentran las escamas, plumas, pelos, cuernos, dientes, uñas y garras, glándulas sudoríparas y sebáceas y las glándulas mamarias. A pesar de esta variedad fenotípica, la organización y el desarrollo de la piel y sus anexos se adhiere a un modelo constante y definido (Carlson, 1990).

Aunque los anexos cutáneos de la piel de vertebrados tales como escamas, plumas, pelos y dientes parecen ser totalmente diferentes, ellos comparten vías de desarrollo común, mediados por Shh, Bmp y Wnt (Wu et al., 2004). El origen evolucionario de éstos ha sido tema de gran interés, considerando que el tiempo ha modificado los anexos según las necesidades de cada especie.
Con exepción de los peces y reptiles, los anexos cutáneos están compuestos exclusivamente de células epidérmicas y el concepto actual es que tanto el epitelio como la dermis son dadores y receptores de información; de este modo el desarrollo morfológico de la piel depende de un diálogo continuo entre estos dos componentes (Dhouailly et al., 2004). Esta comunicación bilateral se desarrolla inicialmente por la activación de factores de transcripción y la difusión de señales.

Las interacciones celulares empiezan antes de que aparezca la piel; lo primero es la formación de los progenitores dérmicos y su densificación en el espacio subectodérmico, área donde previamente se han organizado placodas epidérmicas, (Figs.1b-c), de este modo se establecen los campos y patrones para la formación de los anexos (Patrón Macro). Se forma así una piel embrionaria homogénea de epidermis sobre una dermis densa. Luego se inicia y organiza el crecimiento repetitivo de los primordios de anexos (Patrón Micro). El paso final es el desarrollo de estos primordios (placodas) en un anexo maduro (Figs.1e y f) (Olivera-Martínez et al., 2004a).

Desarrollo inicial, formación de la dermis. En un comienzo el embrión está cubierto por una sola capa de células ectodérmicas que descansan sobre una matriz extracelular.

\footnotetext{
* Programa de Magíster en Ciencias Biomédicas mención Morfología, Facultad de Medicina, Universidad de Chile.

** Programa de Doctorado en Ciencias Morfológicas, Universidad de La Frontera, Chile.
} 

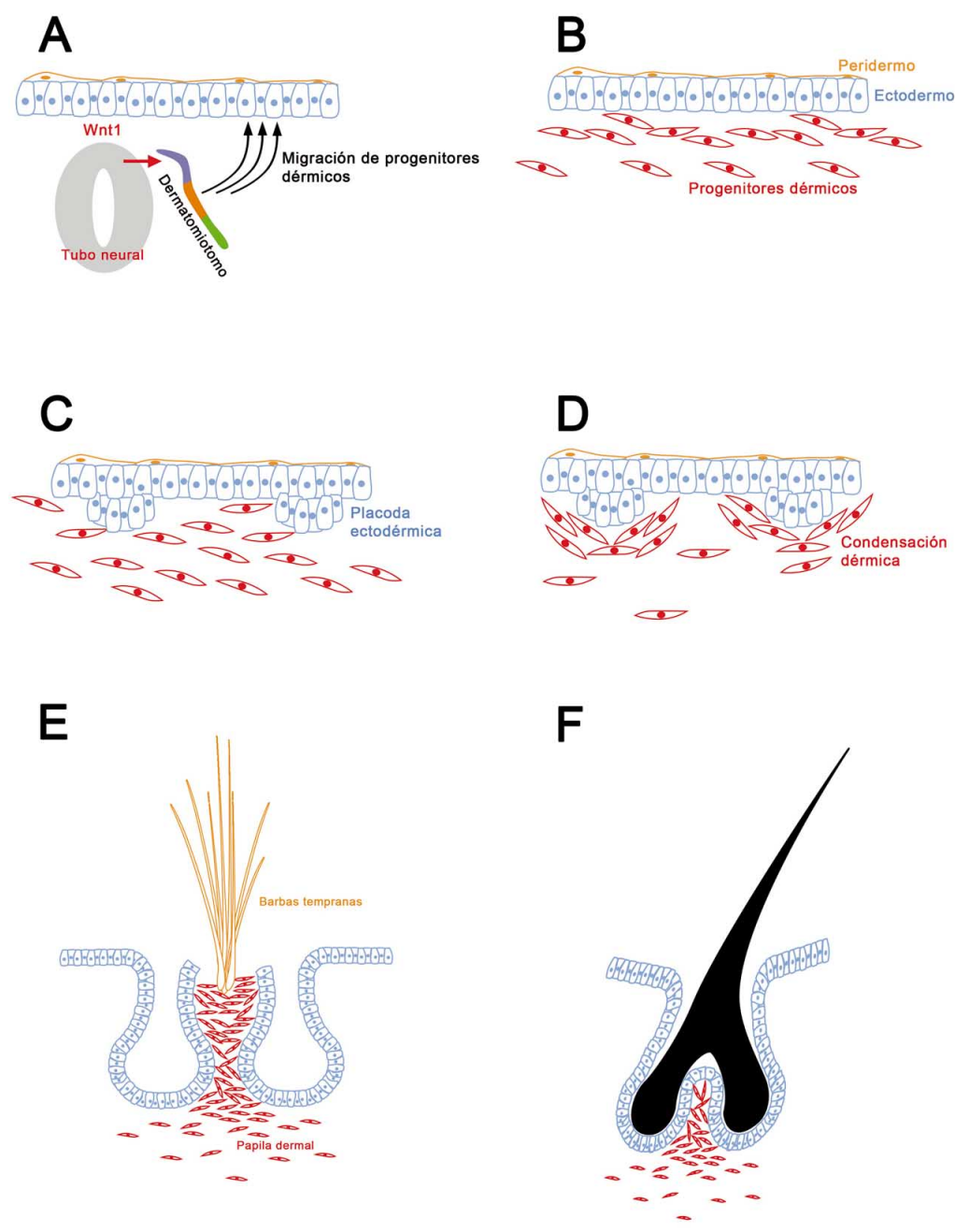

Fig. 1. A y B Ectodermo con 2 capas celulares recibe a los progenitores dérmicos procedentes del dermatomiotomo estimulado por el tubo neural. C y D En el ectodermo se forman placodas celulares bajo las cuales se condensa la dermis. E Formación de una plúmula. F Formación de un pelo.

Luego se estratifica en dos capas; una ectodérmica basal y una fina capa peridérmica superficial. Todos los embriones amniotos tienen peridermo que cubre la superficie antes que el ectodermo se transforme en una epidermis bien diferenciada. Al parecer estas células están implicadas en el intercambio de agua, sodio y glucosa con el líquido amniótico (Carlson, 2005). En humanos el peridermo se puede identificar desde el primer mes (Fig.2a). Luego surge una lámina basal bajo la capa de células ectodérmicas. Al $3^{\circ}$ mes de desarrollo en humanos la epidermis se convierte en una estructura de tres capas; una basal, una intermedia y una peridérmica (Fig.2b). Finalmente a los 6 meses ya se distinguen todas las capas celulares de la epidermis definitivas, se desprende el peridermo y se queratiniza la piel (Fig.2c).

La formación de la dermis comienza conjuntamente con la diferenciación de la epidermis. Las células de la dermis dorsal del embrión provienen del dermatomiotomo (Fig.1a), en tanto que las células de la dermis ven- tral y miembros provienen de la somatopleura (Christ et al., 1983). Las células dérmicas de la cara, de la mayor parte del cráneo y la región anterior del cuello provienen de la cresta neural (Courly \& Le Douarin, 1988). El origen distinto de la dermis posterior y ventral ha sido demostrado mediante heterotransplantes de segmentos de somitos de una codorniz a un pollo (Mauger, 1972).

La aparición de las células dérmicas ocurre entre las 72 hrs y 5 días de gestación en el pollo y entre los 9,5 y 13 días de gestación en el ratón. Posteriormente al 7 día de gestación del pollo se producen condensaciones dérmicas involucradas en la formación de anexos (Fig.1d), originando un área formadora de plumas denominada "pterila", que comienza como una línea de primordios en la región medio-dorsal expandiéndose lateralmente y formando un "patrón micro" en forma hexagonal (Fig. 3). Hay que recordar que la formación de placodas epidérmicas precede a la condensación dérmica (Dhouailly et al.).

Para la especificación de los progenitores dérmicos dorsales desde el dermatomiotomo, se requiere la acción positiva del tubo neural mediante la expresión del gen Wnt-1 (Fig.1a). En el caso de lo progenitores dérmicos provenientes de la somatopleura, los cuales formarán la dermis ventral, no se conoce exactamente el factor de inducción.

Esta dermis está representada inicialmente por células mesenquimatosas poco agregadas pero muy interconectadas mediante uniones estrechas de sus prolongaciones. Comienza así la secreción de una matriz intercelular rica en glucógeno y ácido hialurónico.

En humanos, a principio del tercer mes (en pollos al día 8 y en ratón al día 12), la dermis en desarrollo experimenta una transición desde su forma embrionaria muy celular a un estado más fibroso dado por la diferenciación de fibroblastos que generan una nueva matriz compuesta por fibras de colágeno tipo I y III, más fibras elásticas (Fig. 4). La dermis se vuelve muy vascularizada. 

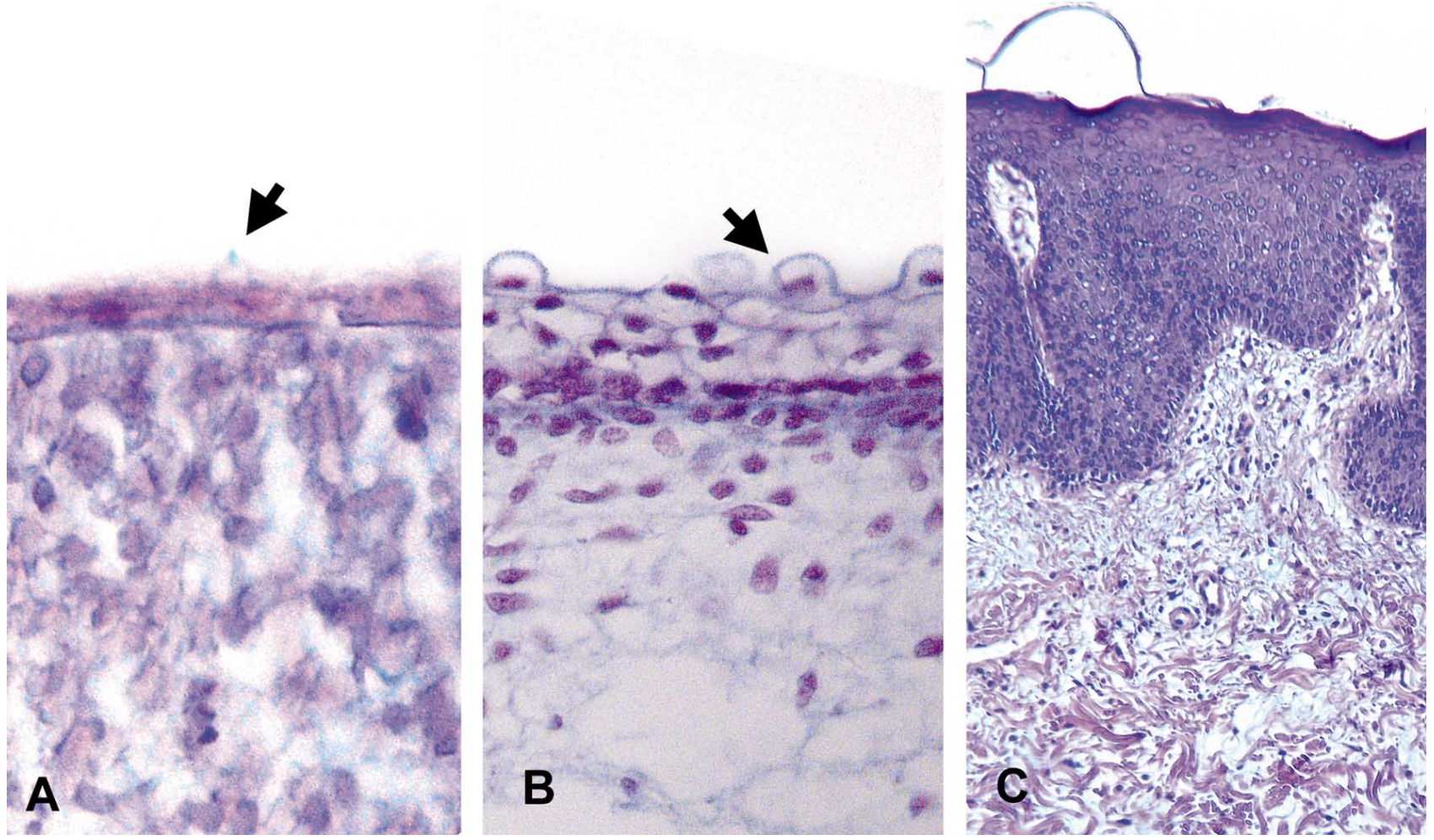

Fig. 2. A Piel de un embrión humano de 8 semanas de gestación. B piel de un embrión humano de 3 meses de gestación. C Piel de un feto humano de 6 meses de gestación. Las flechas indican las células peridérmicas.
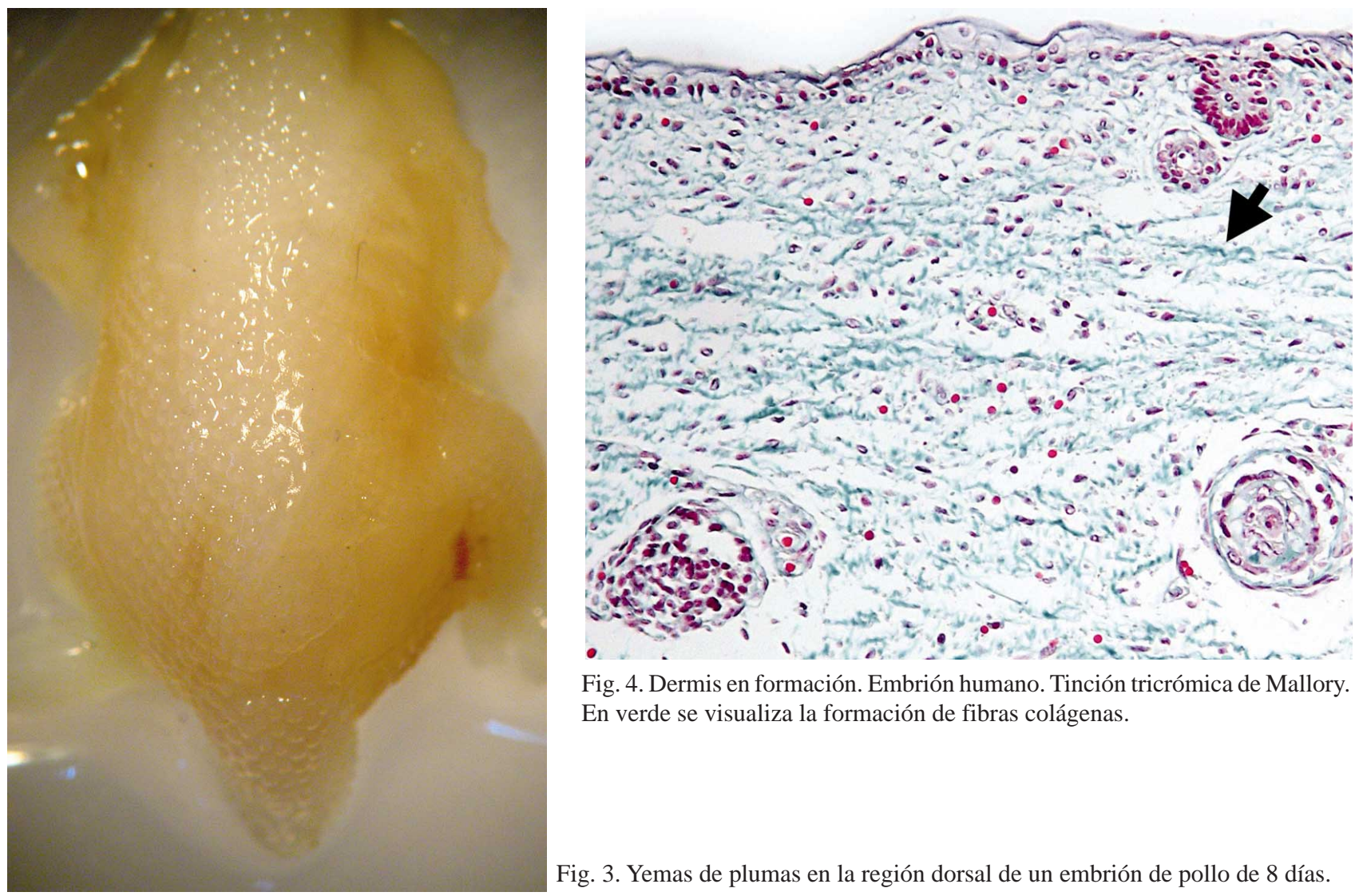

Fig. 4. Dermis en formación. Embrión humano. Tinción tricrómica de Mallory. En verde se visualiza la formación de fibras colágenas.

Fig. 3. Yemas de plumas en la región dorsal de un embrión de pollo de 8 días. 


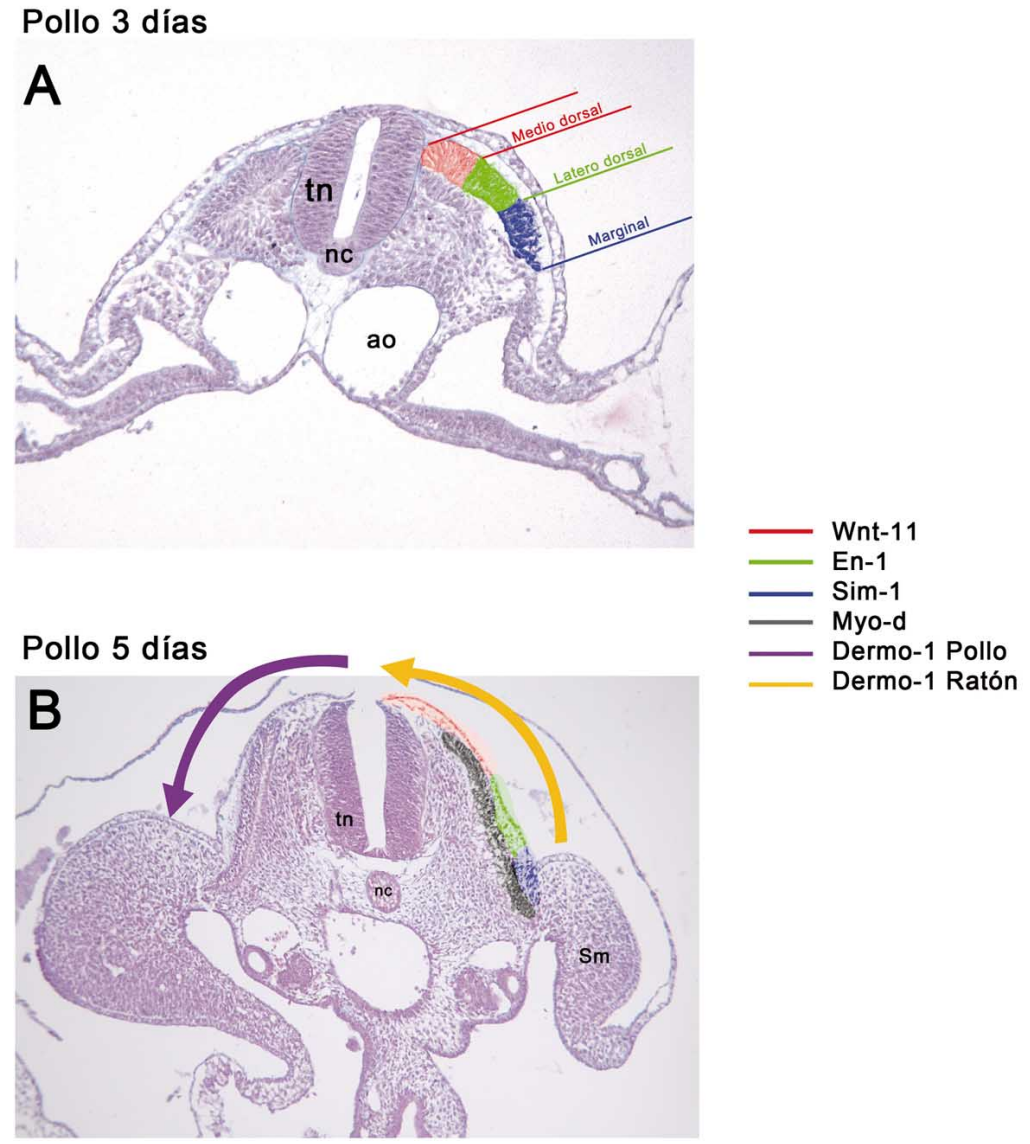

Fig. 5. Cortes transversales de embriones de pollo de tres y cinco días de incubación. En La Fig A se observa el dermatomo del somito en colores, las áreas rojo, verde y azul representan los territorios de acción de los genes relacionados con la formación de la dermis dorsal. En B se representa la expresión temporal de Dermo-1, que en el pollo es de dorsal a ventral (ver flecha lila), mientras que en el ratón es de ventral a dorsal (flecha amarilla). H-E, 100X.

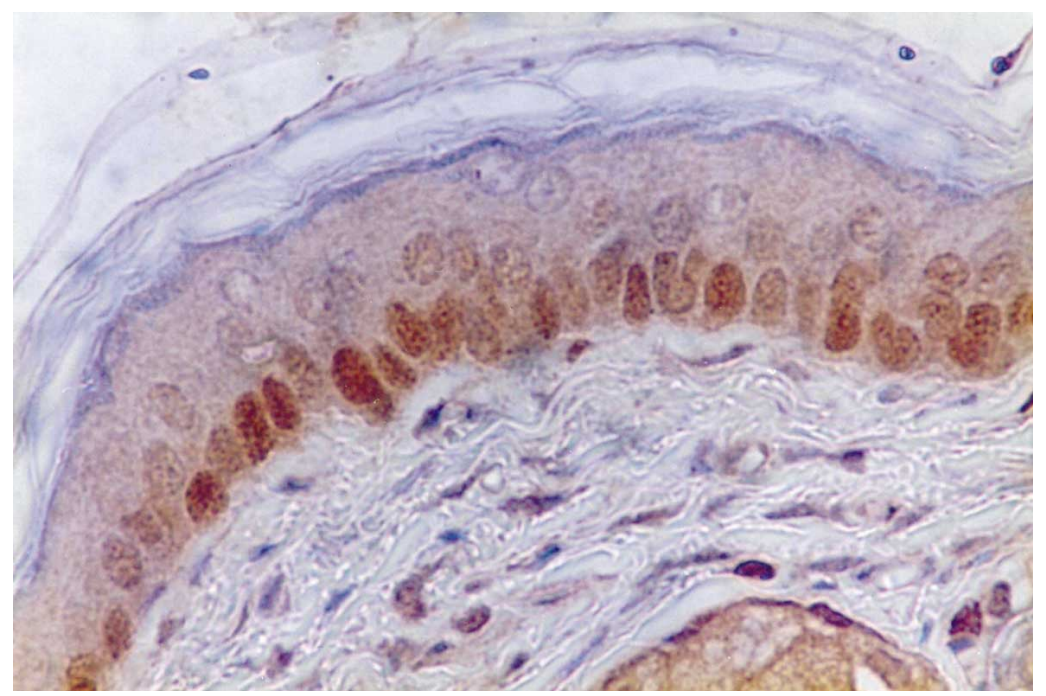

Fig. 6. Corte histológico de piel del roedor Octodón degus prenatal. Tinción inmunohistoquímica Ki67 específica para células basales. 400x.
Poco después los nervios sensitivos crecen en la dermis y epidermis.

Mecanismos moleculares involucrados en la formación de la dermis. El desarrollo de una dermis competente requiere de señales procedentes, en su mayor parte, del tubo neural. En la región dorsal del pollo se ha establecido que hay 3 dominios mesenquimáticos que provienen respectivamente de 3 compartimientos del dermatomiotomo. La señal WNT-1 liberada desde el tubo neural estimula la región más medial del dermatomiotomo a expresar otra señal denominada WNT-11. Se cree que la función de WNT-11 está vinculada con movimientos de formación de dermis densa y condensaciones dérmicas relacionadas con el origen de los anexos. Del mismo modo la señal BMP4 es responsable de la expresión de la expresión de del gen Sim-1 en la región marginal del dermatomiotomo. En la región dorsolateral se expresa el gen En-1, para el cual no se ha encontrado la señal inductora (Fig. 5a). Otra señal relacionada con la densificación dérmica es el marcador Dermo-1 (también conocido como Twist-2), su expresión avanza como una onda de medial a lateral en el pollo y de lateral a medial en el ratón (Fig. 5b).

Respecto a la función de En-1, se cree que actúa como represor transcripcional retardando la expresión de Wnt-11 y Dermo-1 y así formación de la dermis lateral. Por otro lado, Sim-1 actuaría fortificando el efecto de Wnt-1 y Dermo-1 (Olivera-Martínez, 2004b)

Estructuración de la epidermis. Al generarse varias capas celulares en la epidermis, éstas se organizan regularmente y con una secuencia de diferenciación. Las células de la capa basal podríamos considerarlas células madres unipotentes (Fig. 6), ya que se dividen indefinidamente y aportan células a la siguiente capa, que es el estrato espinoso, constituido por células cuboidales distribuidas en multicapas. El movimiento divergente de la capa basal es precedido por una pérdida de adhesión a los componentes de la lámina basal (fibronectina, laminina, colágeno tipo I y IV) que se debe a una pérdida de integrinas (moléculas de adhesión). Las células del estrato espinoso producen filamen- 
tos de queratina, que convergen en los desmosomas distribuidos en forma de parches, uniendo unas células con otras y dando soporte estructural a la piel. El estrato granuloso es la capa más externa con células vivas, las células contienen pequeños gránulos basófilos compuestos mayormente de proteínas ricas en cisteína entre las cuales los paquetes de queratina corren transversos, también hay gránulos lipídicos, que transforman esta capa en una barrera para la pérdida de agua (Junqueira, 2005). Externamente se encuentra el estrato lúcido, compuesto por células muertas que contienen eleidina, una forma intermedia de keratina, usualmente este estrato se hace manifiesto en áreas de piel gruesa como palmas y plantas de los pies. El estrato más externo es el estrato córneo, compuesto principalmente de queratinocitos muertos, en esta capa las células contienen un alto porcentaje de queratina y lípidos, el grosor de este estrato es variable según el segmento corporal (Fig. 7). Esta diferenciación progresiva y constante de la epidermis hacia la superficie genera un equilibrio dinámico, que permite un recambio total de células en un período aproximado de 2 semanas en humanos.

Los gránulos de queratohialina constituyen un marcador de diferenciación epidérmica y su peso molecular aumenta a medida que las células maduran. Por esta razón podemos identificar fácilmente su presencia mediante tinciones inmunohistoquímicas en la piel bien diferenciada (Fig. 7) (Rojas et al., 1998).

Las vías de señalización celular que permiten la diferenciación y reparación del epitelio incluyen varias moléculas, destacando la familia de los factores de crecimiento epidérmico (EGF); dentro de este grupo se encuentra el factor de crecimiento transformantea (TGF-a) con un alto poder para estimular el crecimiento de queratinocitos y migración celular (Vassar et al., 1991). Otros factores importantes son la familia de los factores de crecimiento fibroblástico (FGF), dentro de esta familia está el factor de crecimiento queratinocítico (KGF) que tiene alto poder mitogénico pero poco diferenciador (Byrne et

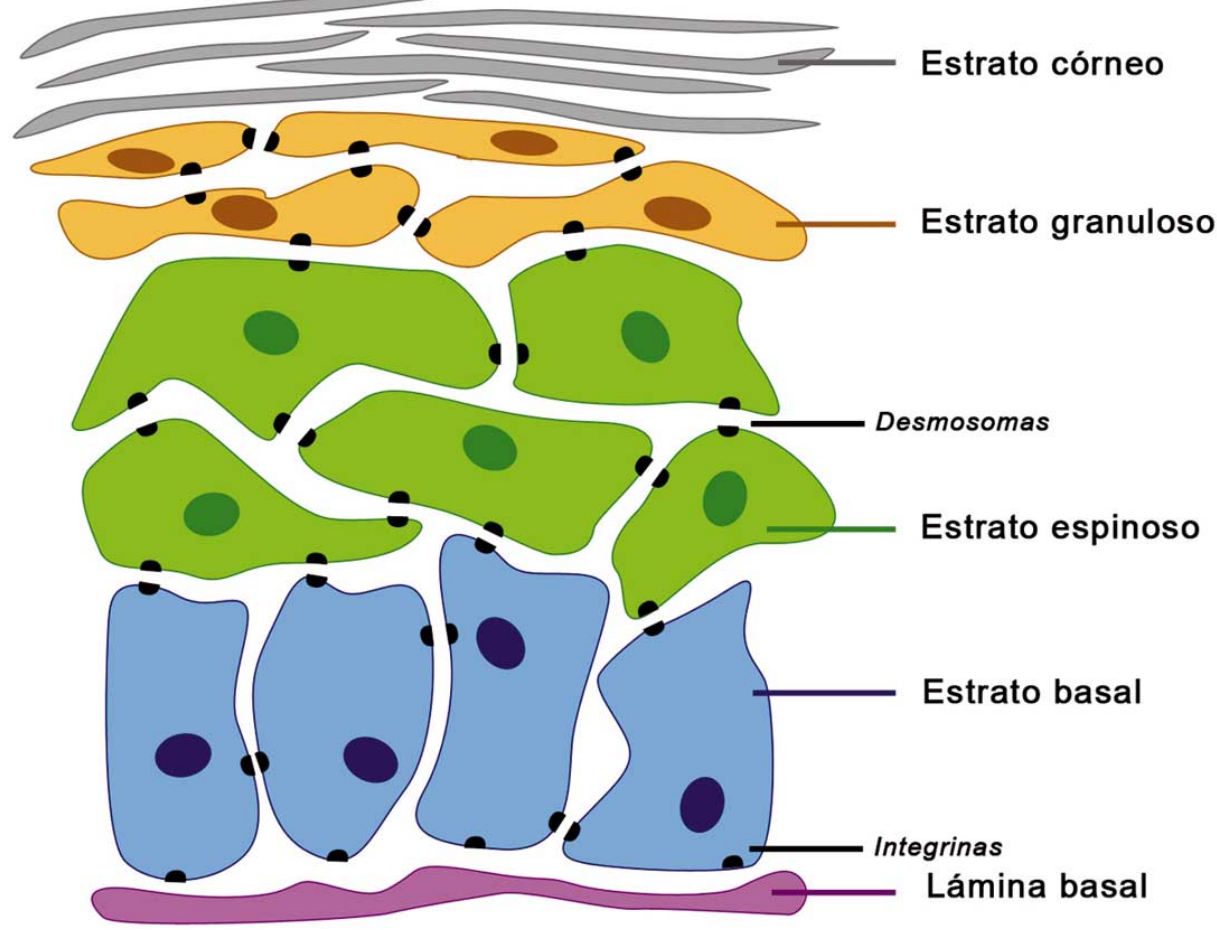

Fig. 7. Estratificación de la epidermis en mamíferos. Los desmosomas corresponden al punto de anclaje de los filamentos de queratohialina y simultáneamente a la unión entre células, mientras que las integrinas son el anclaje de las células basales a la lámina basal. al., 2003). Por último podemos mencionar los factores de crecimiento símiles a la insulina y la interleuquina-1 (IL-1).

Existen células inmigrantes que colonizan la epidermis; dentro de éstas se encuentran los melanoblastos derivados de la cresta neural, la diferenciación de los melanoblastos en melanocitos implica la formación de melanosomas, que son gránulos de pigmento, los cuales contienen melanina en su interior. Las células de Langerhans provienen de la médula ósea hacia la dermis y participan en el sistema inmunitario como presentadores de antígenos. Un último tipo celular, que se desconoce su origen, son las células de Merkel, las cuales están conectadas a terminaciones nerviosas libres y funcionan como mecanoreceptores.

Formación de anexos. Hemos mencionado la importancia de la interación epiteliomesenquimática a la hora de formar los elementos cutáneos, de modo que al formarse una placoda ectodérmica se asocia una condensación dérmica y comienza el desarrollo de un anexo (Fig.1b-e). Esto ha sido demostrado experimentalmente intercambiando tejidos de lugar y entre especies (Dhouailly, 1984). En estos experimentos se ha comprobado la interacción entre el mesénquima (dermis en formación) y el ectodermo para determinar la formación de anexos, su ubicación y su tipo.

Una de las interacciones moleculares más precoces es la EDA/EDAR (Ectodisplasin, una molécula tipo TNF), mu- 


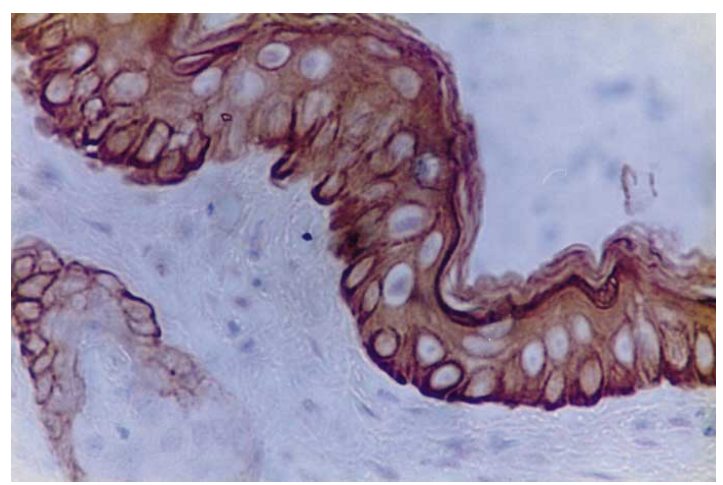

Fig. 8. Corte histológico de piel de Octodón degus prenatal. Inmunotinción para citoqueratinas AE1-AE3, en color café se visualiza el epitelio. 400x

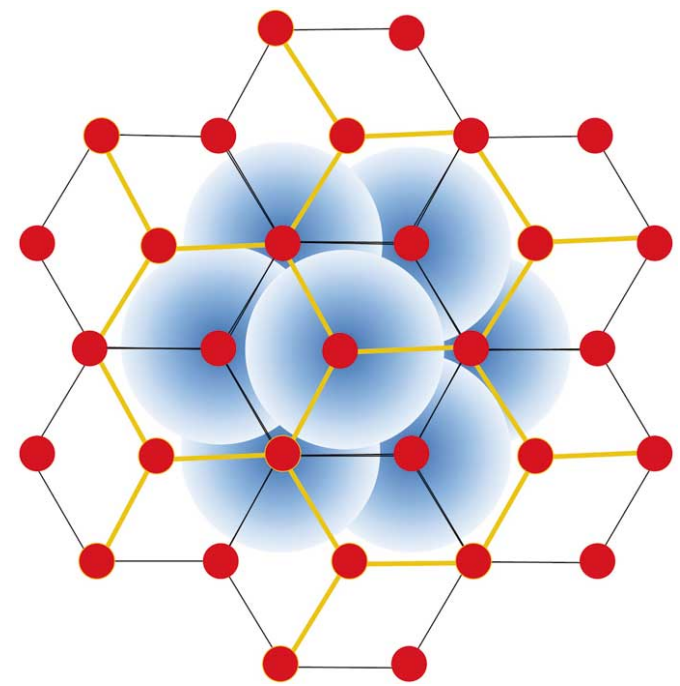

Fig. 9. Principio de "reacción-difusión" propuesto por Nagorcka \& Mooney (1985), en rojo se muestra la concentración de moléclulas activadoras y en azul inhibidoras.

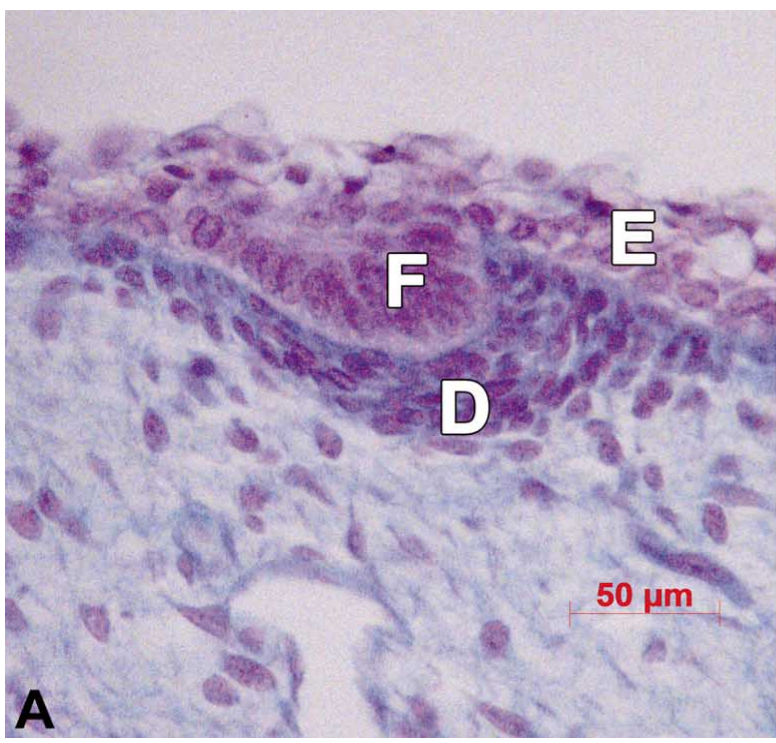

Fig. 10. Primordio del pelo a) En piel de feto humano, H-E azul de Alcián 400X. b) En piel de feto ovino. Tricrómico de Masson 100X. (E) Epidermis, (D) Condensación de células dérmicas, (F) Folículo piloso en formación. taciones en sus componentes producen defectos en folículos pilosos, dientes y glándula sudoríparas, en humanos esta patología se conoce como "Displasia hipohidrótica ectodérmica". Otras moléculas importantes son los factores de crecimiento fibroblásticos (FGFs), la proteína morfogénetica de hueso tipo 2 y 4 (BMP2 y 4) y Wnt. BMP y Wnt actúan disminuyendo el efecto EDA/EDAR (Headon \& Overbeek, 1999).

Un modelo que explica bien la formación de folículos pilosos y su patrón de distribución espacial es el principio de "reaccióndifusión" propuesto por Nagorcka \& Mooney (1985). En este modelo las moléculas activadoras e inhibidoras se concentran en la placoda, pero las activadoras (EDA y FGFs) tendrían una menor capacidad de difusión comparada con las inhibidoras, creando un halo de difusión inhibidor que determinaría el espacio folicular y el interfolicular (Fig. 9).

Es propio de la clase de los mamíferos, Todos los mamíferos tienen pelos, aun que sea en una etapa de su vida. De tal manera que si nunca se desarrollo pelo, significa que no es mamífero. En el ser humano, la conformación del pelo se reconoce inicialmente en las cejas, cuero cabelludo y barbilla del embrión y más tarde se expande por todo el cuerpo en dirección craneocaudal.

En el desarrollo inicial del pelo se identifica un grupo de células epidérmicas basales que se proyectan como una yema en dirección descendente hacia la dermis, a medida que la yema se proyecta, un grupo de células dérmicas comienzan a presionar la punta de la yema creando la papila dérmica, de este modo establece el primordio del pelo (Fig. 10 y 1f).

El pelo incipiente se presenta como un cono de células epidérmicas de rápida proliferación, luego comienza a diferenciarse

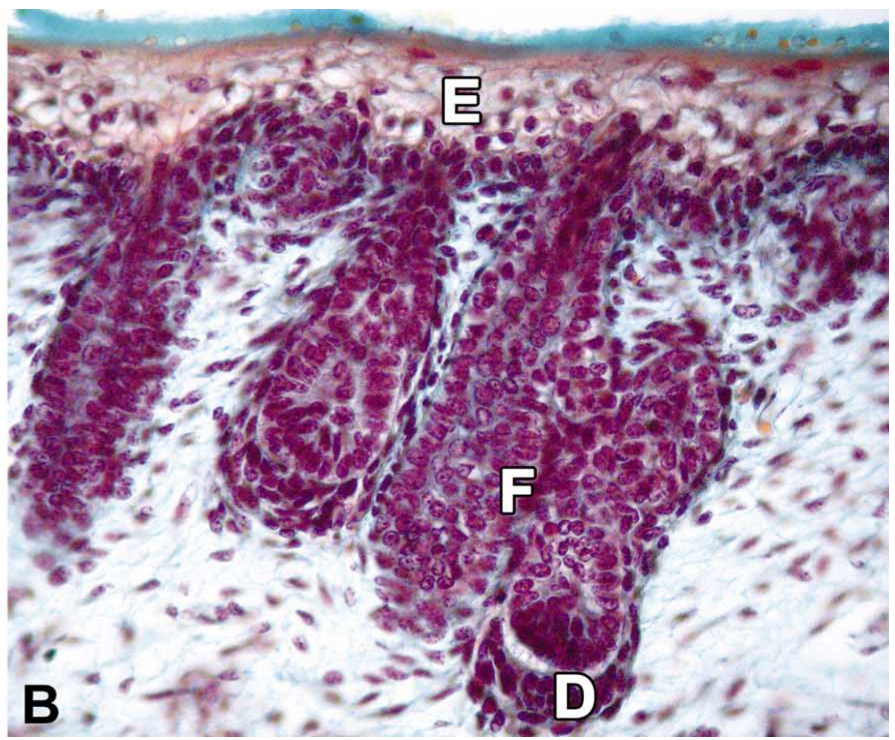


pausadamente, es infiltrado por melanocitos, los cuales se ubican estrechamente en la raíz del bulbo piloso. En humanos al $5^{\circ}$ mes de gestación comienza a queratinizarse la capa de células externas del pelo llamada vaina radicular, formando duros complejos de queratina denominados triacohialina.

Conjuntamente con desarrollo del folículo piloso se forma una glándula sebácea en la porción media de éste y un músculo piloerector, compuesto de músculo liso, que ancla desde la vaina interna a la dermis cercana a un punto cercano a la lámina basal (Figs. 11 y 12).

Las proteínas reguladoras del proceso son principalmente: la influencia estimuladora de FGF-5 desde la papila dérmica y la acción inhibidora de BMP2 y BMP4 desde las zonas laterales. En la medida que se forma el folículo piloso, se comienza a expresar Shh, que estimula la proliferación celular y crecimiento del folículo (Botchkarev \& Kishimoto, 2003).

El folículo piloso ha sido centro de atención de muchos estudios en los últimos años, ya que contiene células madres pluripotenciales al menos en dos zonas de su epitelio. Estas células son una reserva que permite regenerar la epidermis adyacente en caso de lesión tisular, pero no participan de su homeostasis normal (Ito et al., 2005).

Formación de la pluma. Del mismo modo que el pelo, las plumas comienzan de una concentración de células dérmicas bajo una placoda ectodérmica, generando un rudimento que emerge a la superficie de la piel como una yema de pluma ( 8 días en el pollo, Fig. 3) y la epidermis lateral se deprime para constituir el folículo plumoso. El desarrollo posterior depende del tipo de pluma que se desarrolló. En este punto distinguimos 2 tipos principales; las plúmulas y las plumas de contorno las cuales son más alargadas y permiten vuelo.

En el desarrollo de una plúmula, la epidermis engrosada de la yema forma columnas o crestas de la barba que se endurecen y la pulpa dérmica por su parte se retrae. Las crestas comienzan a asomarse al exterior constituyendo las barbas, cada una presenta una estructura ramificada conocida como bárbula (Fig.13). La estructura de las bárbulas difiere entre especies y sirven como marcador.

En la formación de la pluma de contorno, se produce la misma formación de columnas o crestas,

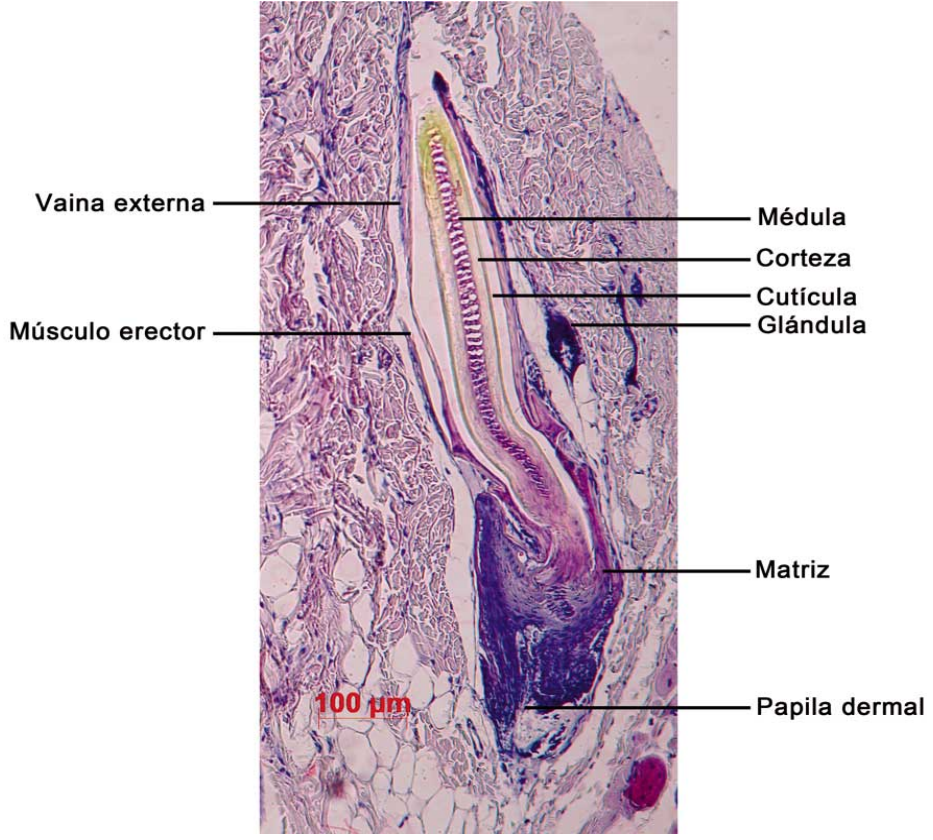

Fig. 11. Morfología de un folículo piloso de rata, tinción HE, 100x.

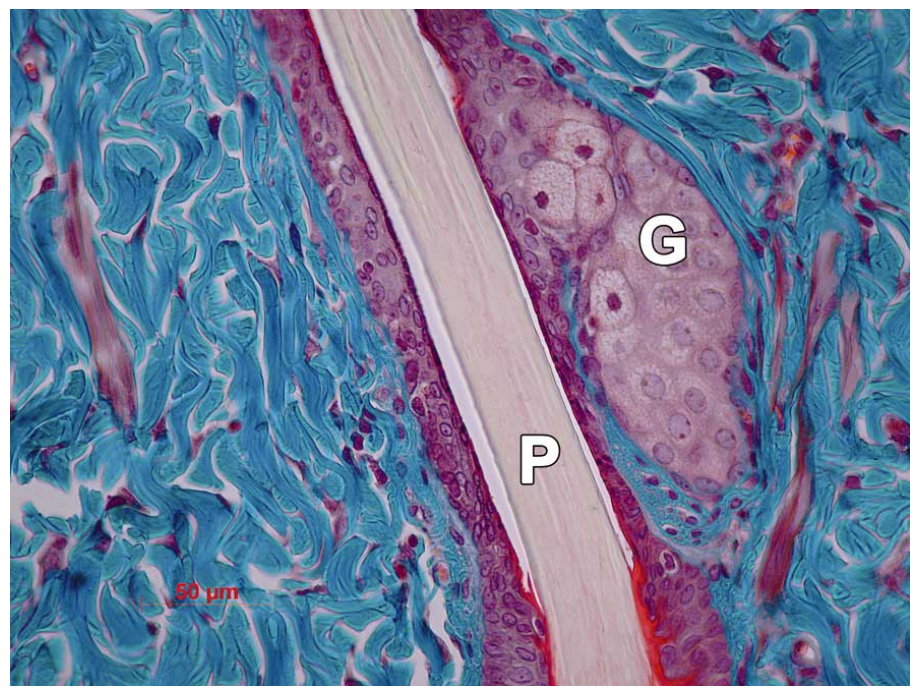

Fig. 12. Corte histológico de la porción media de un folículo piloso de rata, tinción tricrómica de Masson, 400x. (P) pelo, (G) glándula sebácea.

pero adicionalmente se produce una vara principal denominada raquis ubicada en posición posterior que une a las anteriores en una forma cónica y al emerger se abren las columnas dando es aspecto típico de la pluma.

Cada pluma se encuentra asociada a 2 músculos lisos; uno principal que es el erector y un represor que permite que las plumas se replieguen hacia el cuerpo durante el vuelo.

El balance entre las moléculas BMPs y su antagonista NOGGIN juega un rol esencial en la ramificación de la pluma. 


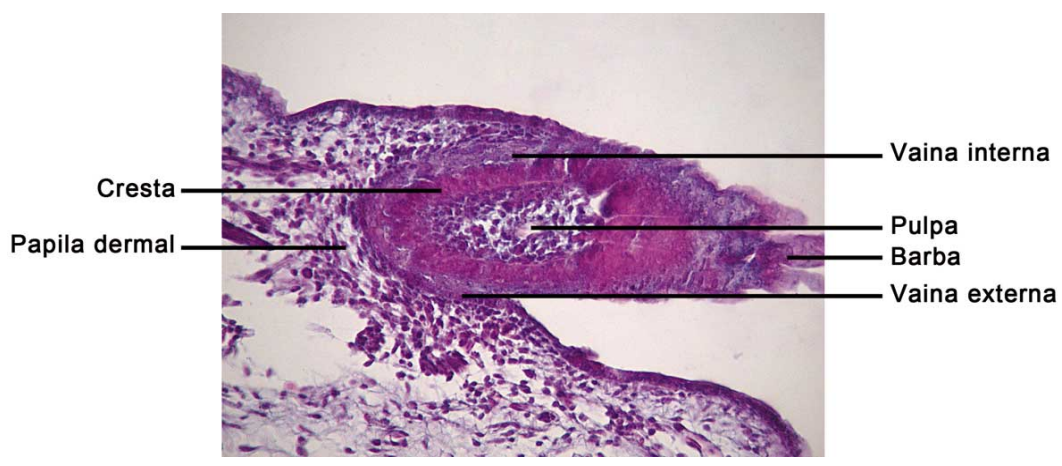

Fig. 13. Morfología de una pluma en desarrollo. Embrión de pollo 20 días. Tinción HE 400x.

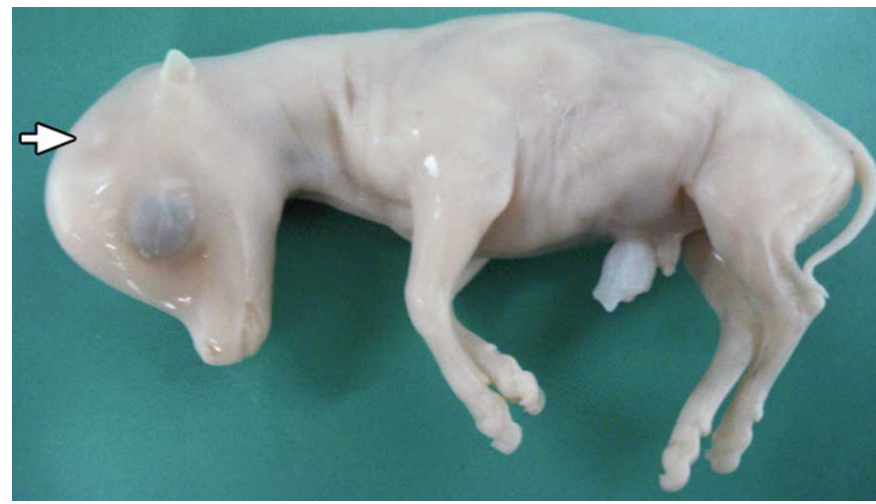

Fig. 14. Cuerno de un feto bovino (flecha)

También la expresión adecuada de BMP y SHH en las crestas es crucial para definir el tipo de pluma y la separación adecuada de las ramas (Yu et al., 2004)

Cuernos y Astas. Dentro de los anexos epidérmicos especiales mencionaremos los cuernos y astas, los mamíferos son los únicos vertebrados con estos anexos verdaderos.

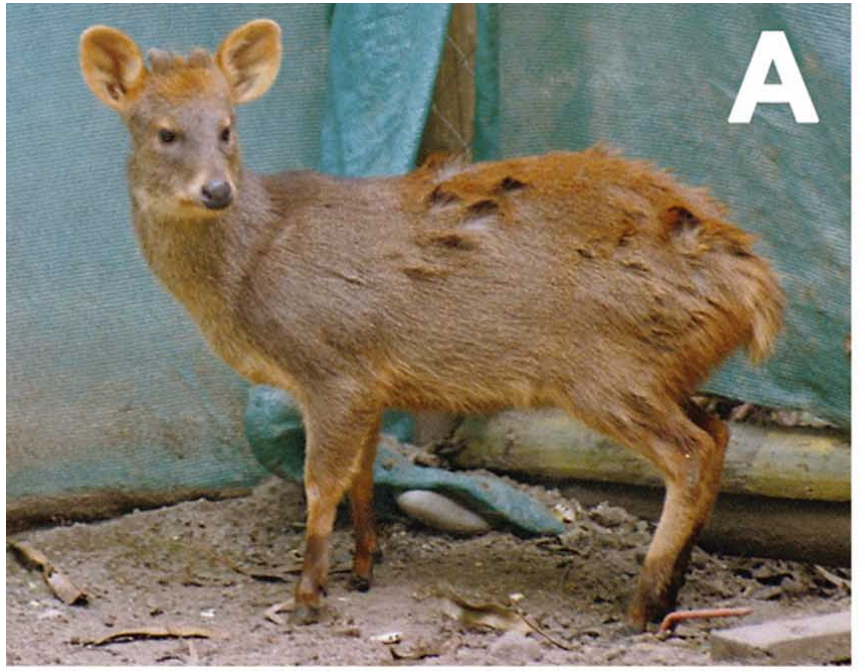

Fig. 15. (A) Astas de pudú, (B) Astas de huemul.
Los cuernos son estructuras pares de los bóvidos, que sobresalen de los huesos frontales, son permanentes, no ramificados, y están conformados por un núcleo óseo y una vaina queratinizada, de crecimiento continuo. Los núcleos de los cuernos comienzan como pequeñas proliferaciones óseas bajo la piel, sobre el cráneo, en el tejido conectivo subcutáneo (Fig.14). No están unidos al cráneo y se los conoce como "osiconos". El osicono posee su propio centro de osificación y se fusiona a los huesos craneanos secundariamente.

Las astas son un par de estructuras óseas ramificadas que sobresalen de los huesos frontales de los cérvidos y se cambian anualmente; están presentes sólo en los machos y crecen a partir de pedicelos, que son estructuras óseas de sostén que se desarrollan en la región lateral de los huesos frontales. Se encuentran cubiertas por piel viva denominada "terciopelo" que proporciona soporte vascular al crecimiento óseo. En un momento determinado por estímulos hormonales, la piel se desprende y el hueso queda descubierto, finalizando el crecimiento óseo (Kardong, 2007).

En la figura 15 se pueden identificar las astas en crecimiento del pudú y del huemul, cérvidos nativos endémicos de Chile.

Armadura dérmica. En algunas especies existe lo que se llama "hueso dérmico" el cual se encuentra asociados a gran variedad de estructuras. Como lo mencionaremos en la siguiente sección es parte de las escamas de los

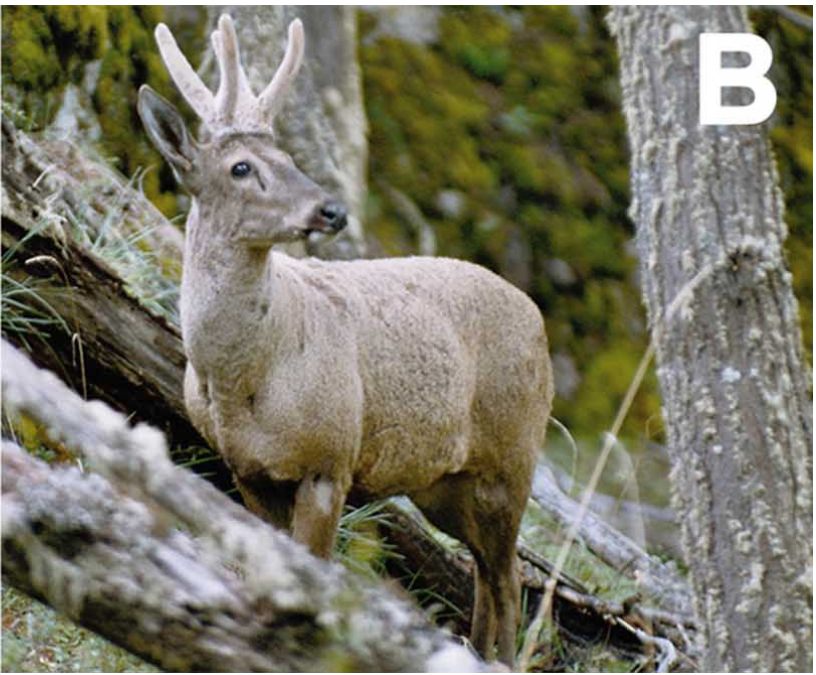


peces óseos, pero tiende a desaparecer en los tetrápodos, siendo casi inexistente en aves y mamíferos con excepción del armadillo (Fig. 16).

El caparazón de las tortugas es una estructura compuesta. La mitad dorsal es caparazón, formado por la fusión de hueso dérmico con costillas expandidas y vértebras (Fig.17). La mitad ventral es el plastrón formado por huesos dérmicos fusionados a lo largo del vientre. Toda esta estructura se encuentra recubierta por placas queratinizadas de epidermis.

La piel de los peces. La epidermis de los peces está cubierta de células vivas, a diferencia de la piel de los vertebrados terrestres que contienen una lámina externa de células queratinizadas muertas. La queratinización es poco común en peces, ocurre en algunos puntos sitios específicos sometidos a roce como órganos de adhesión, labios y superficie de algunos peces capaces de salir del agua. En peces adultos la epidermis está compuesta de varias regiones; el estrato superficial está compuesto de una sola capa de células, la cual provee el color ornamental externo, con un patrón específico de cada especie, superficialmente está cubierta por una abundante cantidad de glicosaminoglicanos los cuales protegen del roce y del ataque de bacterias, hongos y parásitos. Esta capa externa no es renovada periódicamente y cada célula es reemplazada individualmente cuando muere. El estrato intermedio está compuesto de una capa variable de células que incluye células glandulares unicelulares productoras de glicosaminoglicanos, otras productoras de sustancias de alerta y otras productoras de repelentes tóxicos. En este estrato podemos encontrar además células indiferenciadas que sirven de reserva y se dividen cuando es necesario. En la figura 18 se identifican células glandulares caliciformes presentes en el corte histológico de un alevín de salmón.

La tercera región en profundidad de la epidermis es la capa basal, cuya función es anclar el epitelio a la membrana basal, durante el desarrollo estas células cumplen funciones adicionales como: la producción precoz del colágeno dérmico, interactuar con el mesénquima subyacente para el desarrollo de las escamas y probablemente tienen un rol en depositar sustancias epidérmicas en la cara posterior de las escamas (Le Guellec et al., 2004).

La organización epidérmica en estos 3 estratos es casi la misma en todos los peces teleósteos. Adicionalmente encontramos terminaciones nerviosas libres en conjunto con las células epidérmicas.

La piel de los peces es considerada como un órgano respiratorio accesorio, la capa superficial de la dermis es muy vascularizada permitiendo el intercambio gaseoso.

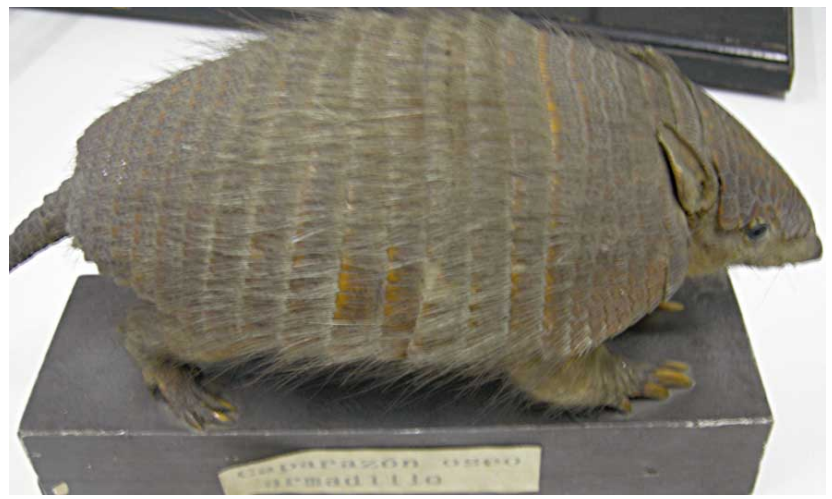

Fig. 16. Armadillo. Mamífero con caparazón compuesto de hueso dérmico.

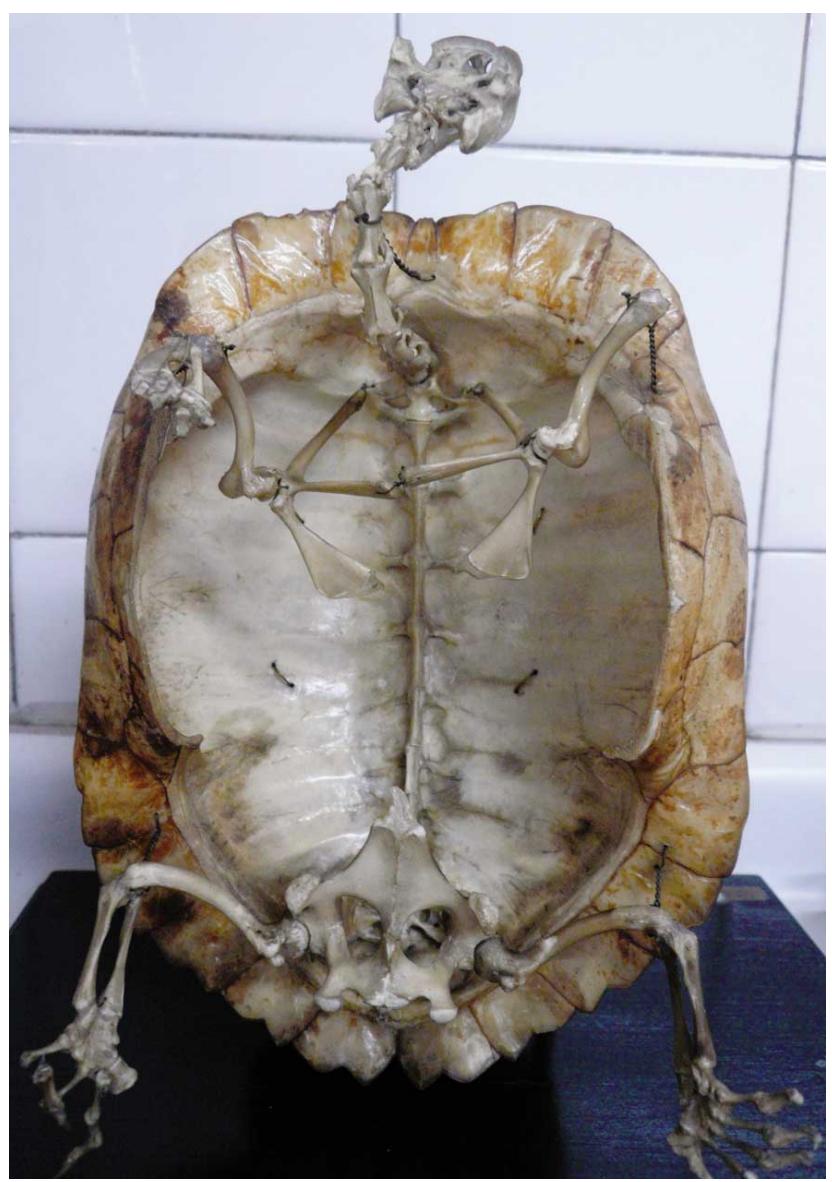

Fig. 17. Visión interna de un caparazón de tortuga, se observa la fusión del esqueleto axial con el hueso dérmico.

La dermis puede ser dividida en 2 regiones: (1) superficial denominada estrato laxo compuesto de fibras colágenas sueltas, numerosos fibroblastos, nervios, algunas células pigmentadas y escamas. (2) Profunda o estrato compacto, caracterizado por una organización de colágeno denso con pocos fibroblastos, en las especies 


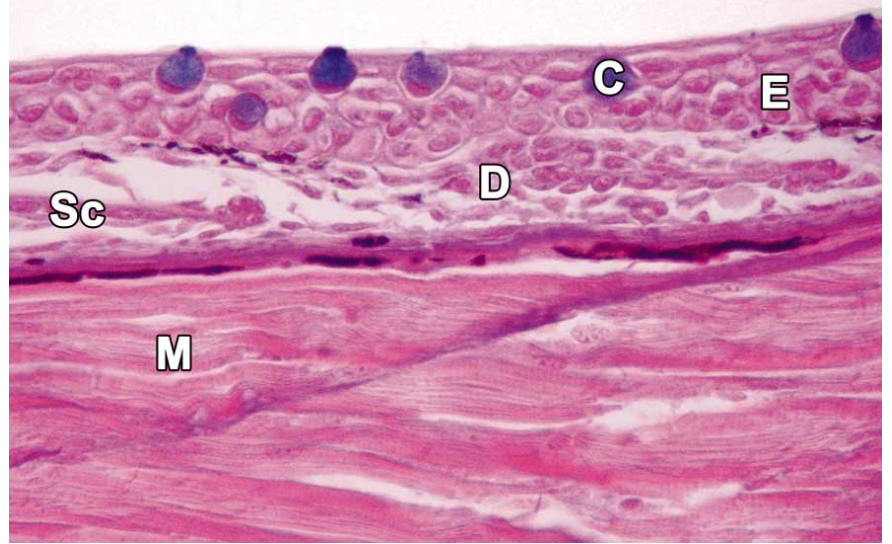

Fig. 18. Corte histológico de piel de un alevín de salmón. Tinción H-E, Azul alcián. Aumento 400x. (E) Epidermis, (C) Glándula caliciforme, (D) Demis, (Sc) Escama dérmica, (M) Músculo estriado.

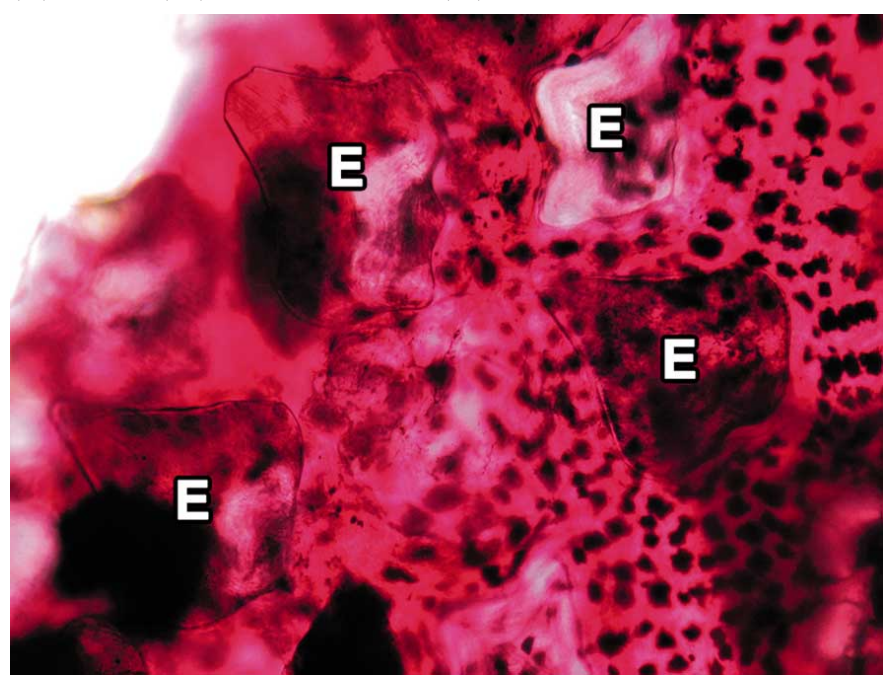

Fig. 19. Piel de un tiburón, transparentada in situ. Se observan las escamas o dentillo cutáneo (E).

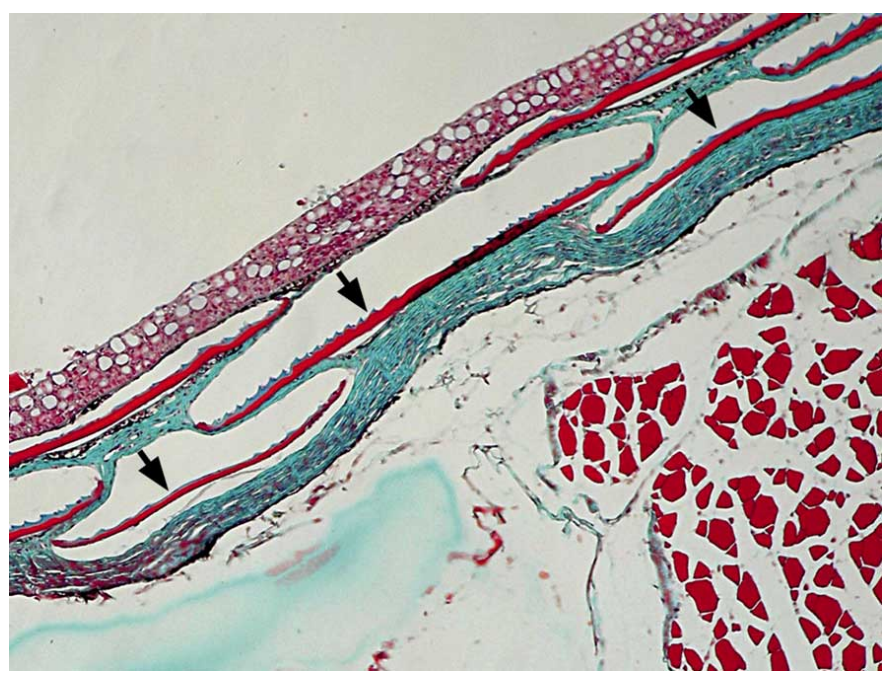

Fig. 20. Corte histológico de piel de un alevín de salmón. Las escamas de teleósteos se forman en la dermis por osificación directa, cavidad de las escamas (flechas). Tinción tricrómica de Masson 100X. sin escamas esta capa predomina. Además de proveer fuerza tensil, la dermis se organiza, en algunas regiones, de forma lamelar proveyendo un aspecto transparente similar a la córnea. En peces, a diferencia de aves y mamíferos, muchos cromatóforos se encuentran en profundidad a continuación del estroma de colágeno.

La hipodermis separa la cara interna de la dermis de la musculatura subyacente; en la piel ya diferenciada está compuesta de colágeno suelto, cromatóforos (melanoforos, iridoforos y xantoforos), vasculatura y un número variable de células adiposas dependiendo de la especie.

Le Guellec et al. mediante estudio de microscopía electrónica han reportado, que en el desarrollo inicial de la piel de los peces, las células epiteliales basales sintetizan colágeno fibrilar y no fibrilar el cual atraviesa la membrana basal en forma de procolágeno y concomitantemente esta dermis es invadida por los fibroblastos que continuarán la producción de colágeno.

Formación de escamas. Las escamas de los peces tienen un origen dérmico y calcificación en peces teleósteos. En peces condriticios, tanto el origen como la forma de las escamas placoideas, se asemejan más a un odontón (elemento que da origen a los dientes) que a las escamas típicas (Fig. 19).

La escama elasmoidea es la más común, presente en la mayoría de peces teleósteos (tilapia, salmón, pez cebra, etc.) se presenta en líneas horizontales y verticales formando un patrón regular. Su origen, al igual que otros elementos óseos de origen dérmico (ej: huesos membranosos), se forma sin necesidad de un elemento inicial cartilaginoso. Se desarrollan en cavidades dentro de la dermis (Fig. 20), cada escama consta de 3 capas; primero se desarrolla la capa externa compuesta por una red de fibras colágenas y tejido bien mineralizado, luego se forma la capa basal compuesta de un tejido parcialmente mineralizado llamado elasmodina y finalmente se forma la capa límite compuesta de fibras hipermineralizadas. En la figura 21 observamos la mineralización de una escama mediante la tinción roja de alizarina y Von Kossa.

Las escamas en formación expresan los genes de patched 1 y bmp2. La epidermis, que cubre las cavidades dérmicas con escamas, emite un patrón de $\mathrm{SHH}$ el cual permite el desarrollo posterior del anexo (Sire \& Akimenko, 2004). 

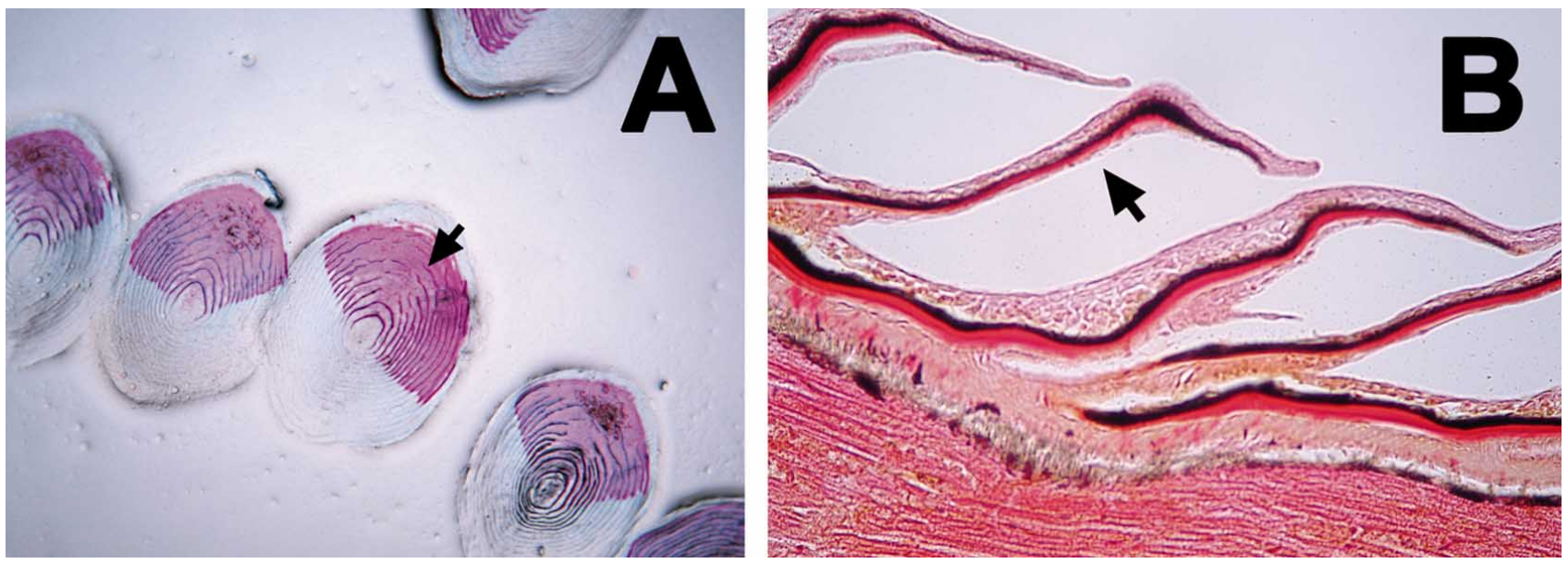

Fig. 21. (A) Escamas de Salmón. Tinción Alizarina in situ 40x. La tinción identifica áreas calcificadas. (B) Escamas de pejerrey calcificadas, tinción de Von Kossa, 100x

AGRADECIMIENTOS: Ilustraciones y edición fotográfica Sr. Simón Saavedra A.

MERUANE, M. \& ROJAS, M. Skin and appendages development in vertebrates. Int. J. Morphol., 30(4):1422-1433, 2012.

SUMMARY: Skin and associated structures allow animals to survive in different ecological environments. The development of skin and appendages in different species has common patterns repeated. Of utmost importance is the epithelial-mesenchymal interaction as the initial controller development. The crucial event in the formation of appendages is the appearance of an ectodermal placode, which is associated with a condensation of dermal cells, expressing BMP and Sonic Hedgehog proteins and then give the way to each species appendages. In this review we describe the successive stages that take place in the formation of the dermis, epidermis and appendages, with emphasis on proteins that direct the process.

KEY WORDS: Skin; Dermis; Epidermis; Appendages.

\section{REFERENCIAS BIBLIOGRÁFICAS}

Botchkarev, V. \& Kishimoto, J. Molecular control of epithelialmesenchymal interactions during hair follicle cycling. $J$. Investing. Dermatol. Symp. Proc., 8:46-55, 2003.

Byrne C.; Hardman, M. \& Nield, K. Covering the limb-formation of the integument. J. Anat., 202:113-23, 2003.

Carlson, B. M. Embriología básica de Patten. México, D. F. McGraw Hill Interamericana., 1990. pp. 367-404.

Carlson, B. M. Embriología humana y biología del desarrollo. $3^{\mathrm{a}}$ ed. España, Elsevier, 2005. pp. 173-207.

Christ, B.; Jacob, M. \& Jacob, H. J. On the origin and development of the ventrolateral abdominal muscles in the avian embryo. An experimental and ultrastructural study. Anat. Embryol. (Berl)., 166:87-101, 1983.

Couly, G. \& Le Douarin, N. M. The fate map of the cephalic neural primordium at the presomitic to the 3-somite stage in the avian embryo. Development Suppl., 103:101-13, 1988.
Dhouailly, D. Specification offeather and scale patterns. In: Pattern Formation. (Ed.) Malacinski, G.M. \& Bryant, S.V. New York, London, Macmillan Pub. Comp.,1984. pp. 581-601.

Dhouailly, D.; Olivera-Martinez, I.; Fliniaux, I.; Missier, S.; Viallet, J. P. \& Thelu J. Skin field formation: morphogenetic events. Int. J. Dev. Biol., 48: 85-91, 2004.

Headon, D. J. \& Overbeek P. A. Involvement of a novel Tnf receptor homologue in hair follicle induction. Nat. Genet., 22:370-4, 1999.

Ito, M.; Liu, Y.; Yang, Z.; Nguyen, J.; Lian, F.; Morris, R. J. \& Cotsarelis, G. Stem cells in the hair follicle bulge contribuye to wound repair but not to homeostasis of the epidermis. Nat. Med., 11:1351-4, 2005.

Junqueira, C. Basic Histology text and atlas. New York, McGraw Hill., 2005. p. 361.

Kardong, K. V. Vertebrados. Anatomía comparada, función, evolución. McGraw-Hill Interamericana, 2007. pp. 209-33. 
Le Guellec, D.; Morvan-Dubois, G. \& Sire, J-Y. Skin development in bony fish with particular emphasis on collagen deposition in the dermis of the zebrafish (Danio renio). Int. J. Dev. Biol., 48:217-31, 2004.

Mauger, A. The role of somitic mesoderm in the development of dorsal plumage in chick embryos. I. Origin, regulative capacity and determination of the plumage-forming mesoderm. $J$. Embryol. Exp. Morphol., 28:313-41, 1972.

Nagorcka, B. N. \& Mooney, J. R. The role of a reaction-diffusion system in the initiation of primary hair follicles. J. Theor. Biol., 114:243-72, 1985.

Olivera-Martinez, I.; Viallet, J. P.; Michon, F.; Pearton, D. J. \& Dhouailly, D. The different steps of skin formation in vertebrates. Int. J. Dev. Biol., 48:107-15, 2004a.

Olivera-Martinez, I.; Thélu, J. \& Dhouailly, D. Molecular mechanisms controlling dorsal dermis generation from the somitic dermomyotome. Int. J. Dev. Biol., 48:93-101, 2004b.

Rojas, M.; Martínez-García, F.; Cobo, P.; Palacios, J.; Nistal, M. \& Regadera, J. Keratinas: biología celular y significado funcional normal y patológico. Rev. Chil. Anat., 16(1):15-31, 1998.

Sire, J.-Y. \& Akimenko M.-A. Scale development in fish: a review, with description of sonic hedgehog (shh) expression in the zebrafish (Danio rerio). Int. J. Dev. Biol., 48:233-47, 2004.

Vassar, R. \& Fuchs, E. Transgenic mice provide new insights into the role of TGF-alpha during epidermal development and differentiation. Genes Dev., 5:714-27, 1991.

Wu, P.; Hou, L.; Plikus, M.; Hughes, M.; Scehnet, J.; Suksaweang, S.; Widelitz, R.; Jiang, T. X \& Chuong, C. M. Evo-Devo of amniote integuments and appendages. Int. J. Dev. Biol., 48:24970, 2004.

Yu, M.; Yue, Z.; Wu, P.; Wu, D. Y.; Mayer, J. A.; Medina, M.; Widelitz, R. B., Jian, T. X. \& Chuong, C. M. The developmental biology of feather follicles. Int. J. Dev. Biol., 48:181-91, 2004.

\section{Dirección para correspondencia: Dr. Manuel Meruane N. Av. Kennedy 7301 Dpto. D-104 Santiago \\ CHILE}

E-mail: mmeruane@vtr.net

Recibido : 30-04-2012

Aceptado: 16-08-2012 